\title{
MORTE E VIDA PROEJA LEITURA, ESCRITA E EXPERIÊNCIA DE VIDA
}

\author{
Aytel Marcelo Teixeira da Fonseca (UERJ e FCCAA) \\ aytelfonseca@yahoo.com.br \\ José Enildo Elias Bezerra (IFAP) \\ enildoelias@yahoo.com.br
}

\section{Introdução}

Nosso objetivo, com o presente trabalho, consiste em relatar uma experiência de leitura e de produção de texto literário com alunos da modalidade EJA (Educação de Jovens e Adultos) de um instituto federal de ensino técnico em Pernambuco. O ponto de partida foi o Morte e Vida Severina, do também pernambucano João Cabral de Melo Neto, e o ponto de chegada, a peça Morte e Vida PROEJA, dos próprios estudantes.

Pretendemos ainda, por meio do relato, evidenciar a necessidade de se considerarem as especificidades do público da EJA no processo de ensino-aprendizagem, o que aponta para uma formação mais sólida dos professores, principalmente de língua portuguesa.

Com vista a tornar a prática pedagógica mais eficiente, baseamo-nos nas concepções teóricas desenvolvidas por Cosson (2009), Jouve (2002), Lerner (2002) e Soares (2010).

\section{Perfil dos alunos}

Os estudantes envolvidos no trabalho estavam matriculados, em julho de 2010, nos cursos de mecânica industrial e de refrigeração de um programa de jovens e adultos (PROEJA) do Instituto Federal de Educação, Ciência e Tecnologia de Pernambuco.

Tinham idades variadas, de 25 a 55 anos, o que justifica a diversidade de experiências de vida existente em sala de aula. Mas em vez de conflitos de geração, solidariedade e entrosamento.

Grande parte deles interrompeu os estudos na juventude, por variados motivos: necessidade de trabalhar para sustentar a família (a 
principal razão), falta de interesse pela escola, escassez de unidades de ensino etc.

Agora, eles retornam à sala de aula e esperam acolhimento e um ensino que mantenha coerência com suas reais necessidades, como, por exemplo, a melhoria nas condições de trabalho, almejando maiores salários e, consequentemente, mais qualidade de vida.

Outra constatação relevante diz respeito ao histórico limitado de leituras de textos literários. Muitos dos estudantes nunca tinham lido qualquer romance ou livro de poema, apresentando dificuldades na construção de sentidos e mesmo alguma resistência inicial ao trabalho com a obra de João Cabral de Melo Neto.

\section{O desafio}

A resistência inicial de alguns estudantes à leitura de texto literário aguçou ainda mais nosso desejo de superar o desafio a que nos lançamos.

Pretendíamos ler efetivamente a obra Morte e Vida Severina, de modo a considerar as vivências do aluno, que precisa alcançar não apenas o sentido, resultado do deciframento da obra, mas também (e sobretudo) a significação, relacionada à maneira particular como reage ao texto, que detém o poder de mudar a existência do sujeito (JOUVE, 2002).

Em outras palavras, não nos daríamos por satisfeitos apenas com o falar sobre a obra, com uma explicação para cada verso (processo comum nas escolas), almejávamos ainda o falar com a obra, ou seja, o diálogo estabelecido entre o criado no universo literário e o existente na vida do aluno, respondendo às indagações: como o livro pode mudar a existência do estudante? O que há do leitoraprendiz nesse texto, de modo que, ao chegar à última página, ele aprenda mais sobre si mesmo?

Por trás desse objetivo, nossa crença na ideia de que, quanto mais o leitor se identifica com o texto, melhor e mais proveitoso será o processo de construção de sentidos. 


\section{O estigma}

Todo desafio pressupõe obstáculos. O primeiro advém dos materiais didáticos disponíveis, raramente voltados para as particularidades da EJA, ora com uma linguagem infantilizada, ora saturados de conteúdos, nomenclaturas, exercícios repetitivos, que em nada satisfazem as necessidades dos discentes.

Por tal motivo, ao procurarmos materiais didáticos para fundamentar e facilitar nosso projeto, não tivemos êxito. Em relação ao trabalho com a leitura, observamos, quase sempre, o estudo de fragmentos de textos, resumos de obras do cânone e o predomínio de textos referenciais, informativos, com pouquíssimo destaque para poemas e contos, por exemplo.

Além disso, enfrentamos um desafio maior: a superação de um estigma, reforçado pelo senso comum e mesmo por outros professores da instituição federal de ensino: "EJA não precisa de Literatura", "Esses alunos nunca conseguirão ler um texto mais denso".

Nessas afirmações, exemplos de preconceito. Por um lado, subestima-se a capacidade do aluno e limita-se seu objetivo ao estudar, como se seu interesse fosse apenas por melhores oportunidades no mercado profissional, sem necessitar do prazer estético proporcionado por uma obra de arte. Por outro lado, supervaloriza-se o texto literário, considerado o "suprassumo cultural", algo disponível para um público seleto, comprovando uma atitude claramente elitista.

Se os estudantes não leem textos literários, realidade que enfrentamos em sala de aula, não é por uma incapacidade cognitiva ou algo parecido, mas justamente por esses dois motivos apontados (entre outros tantos): materiais didáticos inadequados e professores descrentes e detentores de uma visão estreita sobre ensino.

\section{A importância da Literatura: o Letramento Literário}

A concepção de letramento literário (COSSON, 2009), à qual recorremos durante o projeto, desfaz, sem muito esforço, as ideias equivocadas que ouvimos sobre a relação entre EJA e literatura. 
Letramento literário é um tipo específico de letramento, termo já bastante conhecido pelos educadores. Nas palavras de Soares (2010, p. 39), letramento é o "resultado da ação de ensinar a aprender as práticas sociais de leitura e escrita"; ou seja, é mais que apenas conhecer o código linguístico, por englobar o uso da língua em determinada situação comunicativa.

Assim, um indivíduo pode ser alfabetizado, mas não ser letrado:

Alfabetizado é aquele indivíduo que sabe ler e escrever; já o indivíduo letrado, o indivíduo que vive em estado de letramento, não é só aquele que sabe ler e escrever, mas aquele que usa socialmente a leitura, a escrita, pratica a leitura e a escrita, responde adequadamente às demandas sociais de leitura e de escrita (Idem, p. 40).

Uma compreensão equivocada de letramento permite concluir que somente aqueles textos com uma função social bem definida (manual de instrução, bula de remédio, notícia, etc.) contribuem para a formação do estudante. Já os textos literários, em patamar elevado, não participariam do processo de letramento, existiriam apenas para a contemplação.

Por isso, a necessidade de especificar o letramento literário, que deve responder às seguintes perguntas: de que maneira a literatura contribui para a atuação social do leitor? Por que ler um romance ou um poema?

Cosson (2009, p. 17) responde:

A experiência literária não só nos permite saber da vida por meio da experiência do outro, como também vivenciar essa experiência. Ou seja, a ficção feita palavra na narrativa e a palavra feita matéria na poesia são processos formativos tanto da linguagem quanto do leitor e do escritor. Uma e outra permitem que se diga o que não sabemos expressar e nos falam de maneira mais precisa o que queremos dizer ao mundo, assim como nos dizer a nós mesmos.

Dessa forma, a literatura aumenta a percepção de nós mesmos e do mundo, e potencializa nosso diálogo com ele. A partir da experiência relatada por outros, aprendemos mais sobre esse mistério que é a vida. Ler, de fato, pode ser tornar-se mais humano.

Além disso, na literatura, tomamos contato com a linguagem em estado de criação. Daí o encantamento por uma rima, por uma 
construção sintática melódica ou inusitada, por um casamento inédito entre substantivos e adjetivos...

Por esses motivos, em protesto às declarações preconceituosas e infundadas, reforçamos a fala de Cosson (Idem, p. 18):

É por possuir essa função maior de tornar o mundo compreensível transformando sua materialidade em palavras de cores, odores, sabores e formas intensamente humanas que a literatura tem e precisa manter um lugar especial nas escolas.

\section{A superação}

A prática pedagógica com Morte e Vida Severina ancorou-se no trabalho com projeto (LERNER, 2002).

O projeto caracteriza-se por envolver todos os alunos da turma que, dentro de um prazo combinado em equipe e seguindo etapas previamente programadas, caminham para um ponto de chegada em comum, para um determinado produto final (produção de um vídeo, montagem de um jornal, encenação de uma peça etc.).

Organizamos o projeto em três etapas, muito bem delimitadas.

\section{1. $1^{a}$ etapa: foco na oralidade}

Morte e Vida Severina foi lido coletivamente em sala de aula. No decorrer das atividades, instigamos os alunos a falarem sobre o que liam e ouviam.

Como eles conheciam os aspectos geográficos e climáticos retratados no texto de João Cabral de Melo Neto, a compreensão do poema ficou mais fácil e prazerosa.

Os estudantes, identificando-se com as situações vividas por Severino, chegavam a diferentes conclusões. Todas tiveram sua importância registrada, enriquecendo muito mais a aula. 


\section{2. $2^{a}$ etapa: foco na escrita}

Com base nos relatos orais, os alunos redigiram textos, expondo a toda turma e ao professor opiniões, impressões, lembranças revividas durante o contato com o poema.

Trabalhamos com os gêneros discursivos "resenha" e "autobiografia". Por meio deles, os estudantes relacionavam a história de Severino com suas próprias vidas, aprofundando a compreensão do texto.

Mais que atividade valendo nota, "redação escolar", todos esses textos foram oportunidades de nos aproximarmos melhor dos alunos, que tiveram autorização (poucas vezes dada, infelizmente) de escrever, entre os muros da escola, sobre suas próprias experiências de vida, visões de mundo, tendo ao lado leitores interessados.

\section{3. $3^{a}$ etapa: releitura do poema}

Por iniciativa dos discentes, construiu-se a peça Morte e Vida PROEJA, título que expressa uma nova interpretação da obra de João Cabral: a morte significando a desistência, a evasão escolar de muitos colegas, que abriram mão de concluir os estudos; e a vida representando a renovação da luta por dias melhores, a busca por solução para tantas inquietudes surgidas diante de dificuldades enfrentadas dentro da própria instituição, como a inadequação dos métodos de ensino às peculiaridades do público da EJA.

$\mathrm{Na}$ peça, os alunos viraram Sereverinos e a travessia do rio Capibaribe foi representada, metaforicamente, pela superação dos preconceitos sofridos por eles desde o primeiro contato com o instituto de educação.

Traduziram-se as palavras de João Cabral de Melo Neto:

Seu José, mestre carpina, que diferença faria se em vez de continuar tomasse a melhor saída: a de saltar, numa noite, fora da ponte e da vida?

(Texto de João Cabral de Melo Neto) 
Os alunos escreveram:

Seu José, mestre carpina,

Tô pensando em desistir.

Não se tem compreensão cá

Alguns dizem que a velho não se ensina

Ele já deu tudo que tem pra dá.

Nesses poucos versos, um protesto contra a discriminação que enfrentam cotidianamente.

Em outro momento da peça, um diálogo com um interlocutor, Severino explicita as dificuldades que precisa superar, como quase todos os colegas da turma, para continuar os estudos.

Interlocutor

Abriu o vestibular.

Ora, vai lá.

É um programa do governo.

Você volta a estudar.

Severino

Poxa, faz tanto tempo.

A memória faz falhar.

Já não tenho conhecimento.

O que tem pra mim lá?

Interlocutor

A oportunidade é essa.

Você vai alcançar.

E ainda não tem que pagar.

Além de tudo, vale a pena tentar.

Severino

Sei não...

Não sei no que vai dar.

Sou pai de família.

Trabalho.

Cinco filhos pra criar.

Como posso estudar?

Além dos textos, os estudantes produziram o cartaz de divulgação, o figurino e o cenário. Envolvimento total com o projeto. 


\section{Considerações finais}

A partir da experiência que vivenciamos, podemos tirar, no mínimo, três conclusões.

- O aluno, sem a imposição de uma leitura correta, buscou seu próprio significado para a obra. Participou ativamente da construção de sentidos, porque se reconheceu nas palavras de João Cabral. Parte de sua vida estava ali nas páginas.

- Morte e Vida Severina possibilitou aos estudantes manifestarem suas críticas em relação à própria escola. A visão de mundo ficou mais crítica. Em outras palavras, passaram pelo processo de letramento literário.

- Além disso, os alunos envolvidos puderam reconstruir a imagem que faziam de si mesmos, vendo-se agora capazes de usufruir o prazer estético do texto literário e de aprender formas de expressão oral e escrita diferentes das que praticam no dia a dia.

De fundamental importância foi o papel desempenhado pelo professor, o que enfatiza a necessidade de se repensar a formação desse profissional:

O professor de Literatura não pode subscrever o preconceito do texto literário como monumento, posto na sala de aula apenas para reverência e admiração do gênio humano. Bem diferente disso, é seu dever explorar ao máximo, com seus alunos, as potencialidades desse tipo de texto (COSSON, 2009, p. 29).

\section{REFERÊNCIAS BIBLIOGRÁFICAS}

COSSON, Rildo. Letramento literário: teoria e prática. São Paulo: Contexto, 2009.

JOUVE, Vincent. A leitura. São Paulo: Editora UNESP, 2002.

LERNER, Délia. Ler e escrever na escola: o real, o possível e o necessário. Porto Alegre: Artmed, 2002.

SOARES, Magda Becker. Letramento: um tema em três gêneros. Belo Horizonte: Autêntica Editora, 2010. 